\title{
Cultural Intelligence: New Directions for Research in Asia
}

\author{
Shanker Menon ${ }^{1} \&$ Lakshmi Narayanan ${ }^{2}$ \\ ${ }^{1}$ College of Commerce and Business Administration, Dhofar University, Oman \\ ${ }^{2}$ College of Arts and Applied Sciences, Dhofar University, Oman \\ Correspondence: Shanker Menon, College of Commerce and Business Administration. P. O. Box 2509, Salalah, \\ Oman. Tel: 96-82-323-7432. E-mail: s_menon@du.edu.om
}

Received: February 14, 2015 Accepted: March 20, 2015 Online Published: June 5, 2015

doi:10.5539/ass.v11n18p193 URL: http://dx.doi.org/10.5539/ass.v11n18p193

\begin{abstract}
Cultural intelligence is a relatively new area in cross-cultural research. In this paper we describe the construct of cultural intelligence (Cultural Quotient, CQ) and examine the need for more research on cultural intelligence in Asia. We propose that there are many areas that need to be examined as there is a dearth of research in the Asian countries on this subject. We identify specific cultural contexts and environments in Asia where future research on CQ could be done and justify why these specific cultural contexts in Asia may be relevant to CQ research. Four important areas that need to be examined, the measurement of CQ, CQ and its relation to culture-specific variables, CQ and Emotional labor and CQ Education and Training in Asia are briefly discussed. Some recommendations and new directions for future research which will enhance the knowledge basefor both CQ theory and CQ practice in Asia are also discussed.
\end{abstract}

Keywords: cultural intelligence, globalization, emotional labor, Asian cultures

\section{Introduction}

This highly complex globalized world of the 21st century presents several challenges for employers and employees in today's workplace. Globalization has demanded from us interactions everyday with individuals from diverse backgrounds and cultures. This becomes even more challenging when these cultures are vastly different such as cultures with very western values like individualism and cultures with very eastern values like Collectivism (Hofstede, 1980; 2001) and interact with individuals who have been socialized in significantly different ways and fundamental differences in the way they think (Nisbett, 2003).

With the increase in the workforce mobility, we are constantly looking for ways to enhance this intercultural experience and develop cross-cultural competencies and skills. Historically, in the past the focus of intercultural training was on preparing an individual to work in a new culture (Kogut \& Singh, 1988); however, in today's organizations, there is a paradigm shift as individuals are asked to work in multinational environments and move from country to country.

In the past many of these Asian countries have had strong state intervention or many of their businesses and companies were supported in some form by the governments and had been relatively non-competitive. Therefore, many of these individuals have had limited exposure to competition and global environments. So, specifically, for Asia, this kind of research is particularly relevant since many of these Asian countries are only now involved in privatization and globalization (Farrell \& Grant, 2005), and have had less experience in meeting the challenges of the globalized competitive environments that we face today.

There are a number of emerging challenges for global business in Asia today as they try to globalize their organizations (Lasserre \& Schutte, 2006). Many organizations and firms that were traditionally very local are internationalizing their operations by choice or by necessity. There are large groups of people in Asia today who are interacting with other countries and cultures who have had limited exposure and knowledge to adequately understand the cultures that they have to work with. It is important to note that while we speak of Asia as one continent, it is very complex and diverse as there are important cultural differences among the Asian countries and are different in many ways from each other, such as China, Japan and India. For example even within Asia, there have been many challenges such as between Singapore and China (Pereira, 2004). Also, the issues in highly developed countries such as Japan, and Singapore are different from those of less developed countries in Asia. 
An additional challenge in today's global environment is the service-driven economy. As we have moved today from a predominantly manufacturing to a service economy, customer satisfaction, customer relations and customer service are crucial to the success of these global companies (Drucker, 2007). Specifically, intercultural customer service encounters are more challenging due to cultural differences for both customers and service providers. More and more individuals in addition to interacting with other cultures are also frequently engaging in "people work" so there are special emotional demands and display rules where they are expected to display the culturally appropriate emotion. This commercialization of human feeling (Hochschild, 1979, 1983), in this service environment has put additional challenges for individuals interacting with other cultures. So not only do they need the skills and competencies to deal with new cultures but also to meet the challenges of the competitive service-oriented economies. Given these conditions, the challenge for HR managers of these globalized countries is to try ways and means to enhance the skills and competencies needed to adapt to different cultures in this present day competitive global environment.

\subsection{Cultural Intelligence}

A concept that has gained tremendous importance and popularity in recent years and one that is gaining increasing acceptance is the concept of Cultural Intelligence or CQ, this has been defined as individual's capability to function and manage effectively in culturally diverse settings. As interest continues to grow on this subject, several scholars and researchers have come up with a number of papers to address this important concept. In this paper we will introduce the concept of cultural intelligence (Earley \& Ang, 2003) and discuss the concept and its development. We will identify several areas of research where there is a dearth of literature especially in the Asian context. Specifically, we will discuss four areas, the measurement of CQ, CQ and culture-specific variables in Asia, CQ and emotional labor in Asia, CQ and training and education in Asia. We will conclude each section with some recommendations and propositions and offer some new ideas and directions that will enhance the knowledge base for both theory and practice, and the applicability and usefulness of CQ in the Asian context.

\subsection{Measurement and Development of $C Q$}

The seminal work of Earley and Ang (2003), brought to light the construct of cultural intelligence (CQ). This is described as the individual's capability to function and manage effectively in culturally diverse settings, Earley and Ang (2003) posited a convincing theory about this important capability. Although general capabilities such as cognitive intelligence, emotional intelligence, and social intelligence are important they felt that this did not adequately explain individual behavior in certain cultural contexts, especially when individuals interact with other individuals from different cultural backgrounds. What they need, these authors argued, is Cultural Intelligence or CQ (Cultural Quotient). In a series of studies (Ang et al., 2007; Van Dyne, Ang, \& Livrmore, 2010) Ang and colleagues developed and validated a four-dimensional CQ model which consists of 4 measures of CQ which include meta-cognitive, cognitive, motivational and behavioral scales.

In the metacognitive subscale, $\mathrm{CQ}$ focuses on higher-order cognitive constructs and measures one's capability to think about personal thought processes. It also measures one's anticipation of cultural preferences of others, and adjusts the mental models during and after intercultural experiences. Metacognitive CQ is about mental processes that individuals use to learn and understand knowledge about culture.

Cognitive CQ focuses on knowledge of norms and practices, and some conventions in different cultures acquired from their socialization processes including education and personal experiences. These also include knowledge of economic, social and legal systems of different cultures and subcultures. (Triandis, 2006) and also includes knowledge and basic frameworks of cultural values (e.g., Hofstede, 2001). Individuals with high cognitive CQ will better understand the similarities and differences across cultures (Brislin et al., 2006).

Motivational CQ is different from the above two concepts in that this is focused on the capability to direct attention and energy toward learning about, and functioning in situations characterized by cultural differences. Those with high Motivational CQ will direct their attention and energy toward cross-cultural situations. This will include engaging in a wide and flexible repertoire of behaviors.

Finally, the fourth dimension of CQ is Behavioral CQ. This reflects the capability to exhibit appropriate verbal and non-verbal actions when one interacts with others from different cultures. Those with high behavioral CQ will exhibit those appropriate behaviors based on the situation. This will include a broad range of verbal and non-verbal capabilities, and will include exhibiting culturally appropriate verbal behaviors such as words and tone, and non-verbal behaviors, such as gestures, and facial expressions (Gudykunst, Ting-Toomey, \& Chua, 1988). 


\section{Cultural Intelligence and Other Cultural Variables in Asia}

Although there have been many studies that have demonstrated the predictive value of cultural intelligence in several contexts there is a crucial need for more research in specific cultural environments, especially in Asia. For example, Kim, Kirkman and Chen, 2008 found CQ to be predictive of international assignment effectiveness. Flaherty (2008) found that it was predictive of integration in multinational teams and expatriate adjustment and performance (Shaffer \& Miller, 2008). The present authors found the predictive value of CQ in several studies done on expatriate samples (Menon \& Narayanan, 2008, 2009, 2011; Menon, Narayanan, Plaisent, \& Bernard, 2011) and observed that there were significant differences between western and eastern countries, especially in Asia.

However, there are many cultural variables particularly important in Asia that may be related to CQ that could be of much interest to both researchers and practitioners that have not been examined in this field. In the following section we will discuss some variables that could be directly related to CQ and be important to consider in the Asian context.

\section{$2.1 C Q$ and Cultural Values}

Our cultural values, beliefs, and attitudes play a major role in shaping our behavior and have a powerful influence on us. Several studies over the last 3 decades have examined this important dimension of human behavior - the cultural value dimensions. Hofstede (1980) in his seminal research developed an influential theory of cultural dimension based on world cultural values data from IBM from 50 countries around the world. More recently, Hofstede (2003) has stated that there are five dimensions to identify and categorize a country's culture. The original dimensions were Individualism, Power distance, Masculinity, Uncertainty Avoidance. Subesequently, the dimension of Long term orientation was added based on research done in China. Two more dimensions that are very important and have been recognized recently (Hofstede, Hofested, \& Minkov, 2010) that differentiate between Cultures are Restraint and Indulgence.

For example, the dimension of Power distance which is the extent to which less powerful members in a culture accept that power is distributed unequally is higher in many Asian countries as there is an appreciation for hierarchy and a top-down strcture in these societies.

Many Asian societies are also more restrained. Compared to indulgent societies people with this orientation have the perception that their actions are restrained by social norms and they restrain themselves from too much indulgence. We propose that more research be done to compare individualistic countries such as USA, Canada and the UK to countries that are more collectivistic such as China, Japan, and India to understand the dynamics of how cultural intelligence specifically relates to cultural values in specific cultural contexts.

It is important to also recognize that even within the Asian countries there are many cultural differences. The Japanese culture can be characterized as highly tacit and group-centered, whereas Chinese culture is more explicit and individualistic ( $\mathrm{Li}, 2007)$.

In a recent cross-cultural study, the present authors (Menon \& Narayanan, 2009) examined the relationships between some cultural dimensions that are unique to specific cultures such as specific values and beliefs, using the framework developed by Hofstede, and how they could relate to Cultural Intelligence. This study compared Asian countries in the east to western counties such as the United States. Two different groups of expatriates who were global professionals were selected from each country. Some significant relationships emerged that were very culture-specific in the eastern and western countries.

Not only were there significant differences in the level of CI for these cultures, there were also significant differences among the occupations in these cultures. These differences underscore the need for us to understand the dynamics of the different $\mathrm{CI}$ scales as they relate to occupational roles, in addition to differences in culture.

We also propose that the relationship of CQ to these dimensions of culture need to be examined specifically taking many of these cultural differences into consideration. There may be some complex dynamics on how predictive CQ will be in these intercultural encounters, given some major differences in cultural values between the western and eastern cultures. In addition, even in Asia, there could be many differences between Confucian cultures such as China and cultures in the Indian subcontinent such as India.

\subsection{The Concept to Time}

Our cultural patterns strongly influence our behavior in relation to time. Today, an important resource in any culture is the effective utilization of time. In cross-cultural encounters, many misunderstandings and 
miscommunications occur as we interact with others whose perceptions of the importance of time differs from our own.

Behavior in relation to time is strongly influenced by cultural patterns some researchers have found important differences in the way countries perceive time (Usnier, 1991). In his research across 5 countries he found that the developing countries he examined tend to favor ideal economic time. This was largely contradictory of their actual behavior, and he feels that this could be a source of misunderstanding with business-people coming from actual economic time countries.

Monchronic cultures such as the US, Germany or Switzerland view time as if it were linear, as one event happening at a time, they are concerned with times, schedules and deadlines. Polychronic cultures are more flexible in their perception of time; they integrate task-oriented activities with socio-emotional ones. They are concerned more with relationship than tasks that are time-bound Polychronic cultures are more flexible in their perception of time. They integrate task-oriented activities with socio-emotional ones. They are concerned more with relationship than tasks that are time-bound (Van Everdingen, \& Waarts, 2003).

In the Asian context for many countries such as India time is not linear, and thus is not as important as to western societies which typically score low on this dimension. In India, there is an acceptance that there are many truths which often depends on the seeker. Societies that have a high score on pragmatism typically forgive a lack of punctuality, and tend to be much more fatalistic and accepting the fated path and not keeping to an exact plan.

The differing perceptions and utilization of time in business settings in different cultures can interfere with meetings, transactions and be very frustrating having several negative outcomes (Brislin \& Kim, 2003). It is very important to know how CQ can be predictive of one's adaptation to these challenges and the relationship of CQ to such cultural variables, especially in the Asian context needs to be studied.

It might be very important to examine how CQ predicts individuals' behavior in cultures which are significantly different in their own. In this highly competitive global environment that we live in, meeting deadlines is a critical factor in most job environments. There are cultures, where time is not given much importance and there is no sense of time urgency. On the other hand, there are cultures that are very conscious and sometimes obsessed with time. There is a dearth of research on how CQ is related to the perceptions of time. It would be interesting to examine the challenges that individuals face in these cultures where time perception is significantly different and examine the role of CQ.

The present authors (Menon, Narayanan, \& Spector, 1996) examined the importance of this concept of time urgency in an earlier study. However, it might be useful to examine time urgency in the context of CQ across different cultures that is different in their perception of time. We propose that specifically more studies be done to understand how CQ is related and what are the specific skills that are employed to adapt to cultures where the attitude and perception of time is vastly different from one another such as a western and eastern culture. More specifically, we propose that researchers examine the role that CQ plays in Asian countries such as China include differences in time sensitive countries such as Japan and other countries such as India.

\subsection{Emotional Labor}

As discussed earlier the service-driven economy that we live in today demands certain display rules of emotion that sometimes can be challenging based on the societal norms of every culture. Hochschild (1983) in her seminal work on flight attendants coined the work "emotional labour" which can be defined as the emotional display required by workers in a variety of occupations, where they are expected to manage their emotions to meet the demands of service. In her book The Managed Heart: The commercialization of human feeling, she explains how in many service-oriented jobs, employees have to abide by feeling rules and techniques of emotion management, and display the appropriate emotion.

In general it is evident that we are worse at recognizing emotions of members from different cultural groups (Elfenbein \& Ambady, 2002) when compared to our own. The service-driven competitive environment requires frequent intercultural encounters between service providers and customers with appropropriate emotional regulation and control. Cultures vary in their emotional display rules (Matsumoto, 1990), and the type of communication style (Holtgraves, 1997).

There are a number of factors that have been examined by earlier researchers such as cultural variations in their emotional display rules (Matsumoto, 1990), communication directness (Holtgraves, 1997) and the different scripts that are culture-specific (Triandis, Marín, Lisansky, \& Betancourt, 1984). These differences create a context in which there is more room for miscommunication and discomfort for the service providers and customers, which can influence emotion regulation. It would be interesting to examine how CQ is related to 
individual's abilities to cope with these emotionally demanding jobs. There have been few studies relating CQ to emotional labor in Asia.

Cultural Intelligence in these situations can be adaptive and more research needs to be done to examine the relationship of CQ to emotional labor in specific cultural contexts in Asia. For example, the dimension of Indulgence versus Restraint values in a culture may significantly affect how we look at customer service in some Asian cultures. In indulgent cultures such as in the USA there may be a perception that customer service should be visibly reflected by a friendly smile and a friendly manner. However, in more restrained cultures in some parts of Asia this would not be considered as an appropriate social norm and be seen as overly unnatural.

There have been few studies that have examined emotional labor and burnout in different cultures which is reviewed below. Hülsheger and Schewe (2011) in a meta-analytic study report that there was a bigger relationship between emotional labor and burnout for the countries like Canada and United States that have an Anglo culture compared to countries such as Spain that have Latin European culture. In Asia, Allen, Diefendorff, and Ma (2013) found that the relationship between emotional labor and burnout was weaker for Chinese than American service workers, and this could be due to cultural values of high emotional control in China and the strong Confucian cultural values.

We propose that given the challenges of a service driven economy, we need to understand how these affect the emotional labor of individuals in Asian cultures Also, as some researchers point out the original research on emotional labor (Hoschild, 1979) was based mostly on a western sample in a specific cultural context (Mesquita \& Delvaux, 2013) So there is much research to be done on the role of CQ and emotional labor in Asia.

We propose that future studies examine specifically, the display rules and emotional demands that are culture-specific in the Asian cultures and examine the relationship of CQ in adapting to these challenges and demands.

\section{CQ Measurement and Methodologies}

Although previous researchers have developed rigorously tested and validated scales on CQ (Earley \& Ang, 2003), the measures are primarily self-reported measures, and rely on the individuals to report their own perceptions and evaluations of CQ. Although the self-report method is most frequently used in research, there are several limitations to this method, specifically as we attempt to understand this relatively new concept of CQ.

Additionally, since cultural intelligence is a socially desirable trait, responses given may be biased and many self-reports may be socially desirable (Crowne \& Marlowe, 1960) and respondents may respond the way one expects them to respond. It is conceivable that one may not openly express one's attitudes towards other cultures and other groups openly so the self-report method may not be the best way to measure CQ. Case studies, observations, use of simulation exercises and peer reports are some other possible methods to examine CQ must be explored and these will be briefly examined below. Since CQ is still a relatively new concept there is more need for research using these methodologies in specific cultural contexts especially when there is a dearth of research in the Asian context, and we need more culture-specific research on the development of CQ construct in Confucian cultures in countries like Japan and China, as well as other south Asian cultures such as India.

\subsection{Behavioral Measures}

We suggest that future research on CQ for specific cultures, focus on developing behaviorally anchored measures, and also focus on other methodologies such as behavioral observation and other ratings that have been successfully used for evaluation of individuals. One example would be the use of the techniques such as Assessment Center Method.

\subsubsection{Assessment Centers}

Bray began the first industrial use of assessment centers in his research study in AT\&T in the US. Bray, Campbell, and Grant (1974) published a seminal study documenting the long-term effects of the AT\&T program which showed that assessment centers are valid predictors of performance even twenty years later. Typically, in the assessment center, individuals are assessed for a variety of job-related skills and competencies. They participate in various simulation exercises at the individual and group level. These are evaluated by a group of assessors. These simulations include and are not limited to scenarios that require role plays, presentations, in-basket exercises, and group discussions.

Assessment centers now are used and implemented in a number of business organizations in countries around the world. They began their inception in England and the US in the 1950s, assessment centers spread to selected organizations in Canada and Japan, Germany, Switzerland, Israel, South Africa, and Indonesia in the 1970s and 
today with globalization and continuing emergence of global business organizations and multi-national corporations, there is an ever increasing need to design and develop assessment centers that have applicability both cross-nationally and cross-culturally.

\subsubsection{CQ and the Assessment Center}

The Assessment Center literature would be a good base to examine how behavioral measures of CQ could be developed and applied in a variety of contexts increasing our knowledge in practice and theory. The Assessment Center is a popular technique that has been used for over 5 decades now and has proved to be very useful for selection, training and development and promotion, and has gained immense popularity (Thorton \& Rupp, 2004). It has proven to have high predictive validity and in the last few years, very innovative trends have emerged and have been employed in assessment center practice (Howard, 2012). However, this technique has more often been used in western countries compared to countries in Asia.

Although with the growth of Multi-national companies in Asia, it is being introduced in the Asian context, more assessment centers need to be used for employment. For example when we examine the methods used in Assessment Centers, many of these techniques can be applied to evaluate the dimension of CQ. Assessment centers have been successfully used for recruitment, selection and training. There have been no studies, to these researchers' knowledge, that have attempted to do this. To understand how CQ works in a specific cultural context, the use of this type of method would be invaluable and serve as a rich source of data to establish both construct and criterion validity of $\mathrm{CQ}$.

We propose that CQ be measured using the assessment center approach and validated along the same lines in Asian countries. Specific strategies and innovative scenarios can be very effectively developed that are very relevant culturally to the Asia. Many of the cultural variables we discussed that are relevant to the Asian context such as time perception differences, differences in cultural values could also be used as independent variables and the scenarios could be development to examine how predictive CQ is to several performance outcomes.

Quasi-experimental designs could be developed with behavioral exercises, including role-play, leaderless group discussions, in-basket exercises and other measures can be used contextualizing these to cultural intelligence themes. Many of these could be developed from real-life challenges that Asian businesses have faced in the past, where cultural sensitivity and cultural misunderstanding were involved. The assessors that could be used could be both from the home country and the Asian country. Briscoe (1997) had proposed that this type of methodology be used even in the development of the traditional assessment center.

Different dimensions of Cultural intelligence could emerge that are very relevant to specific cultures in Asia from this method. This could enhance not just the predictive and criterion validity but help us to understand the construct of CQ in specific cultural contexts in Asia, thereby enhancing its construct validity.

\section{Qualitative Measures}

Many of the measures that have been used are primarily quantitative; we propose that more qualitative measures also be used to capture the nature and context of specific cultures. We believe that cultural differences in general have been underestimated, and it is important that future research come up with unique methodologies, including ethnographic methodologies to capture the idea of how CQ operates in a specific culture.

\subsection{Culture-Specific Methods}

The present authors have done a variety of studies using qualitative methodologies. For example in a culture-specific examination of the five factor model of personality, the present authors developed a unique method (Narayanan, Menon, \& Levine, 1995), and also to measure the culture-specific nature of stress with a qualitative methodology (Narayanan, Menon, \& Spector, 1999a, 1999b). Future research on CQ should come up with innovative ways to measure CQ such that this would be embedded in the context and culture that it is examined in, therefore we would be able to understand how CQ is predictive of the individuals behavior in specific contexts in specific cultures such as Asia.

\subsection{The Use of Case Studies}

We feel that one area that has been underused and where there is a crucial need for more research is the use of real-life examples to understand CQ. There have been so many business cases in Asia, that are rapidly developing both technologically and economically that have involved multiple countries and cultures, where projects, business ventures, new alliances, partnerships have failed or have been unsuccessful or completely collapsed. On the other hand, there have been so many instances of highly successful business partnerships and business success between countries and cultures (Earley \& Mosakowski, 2004). Although, there are several 
reasons for these successes and failures and while many other variables are involved, this is a vast resource of potential data for the understanding of CQ. Future research should focus on these huge amounts of archival data that we have, and these real-life examples and try to understand these cases to see if some of them are relevant to the role of CQ and if they can be analyzed from the perspective of CQ. In-depth qualitative analysis, content analysis and ethnographic research approaches can be used to explore themes relevant to specific cultures in Asia and its relations to CQ that could emergence from the use of and emic approach to understand this process. Not only could important lessons be learned, but we can better understand the predictive and criterion validity of CQ in this process.

\section{CQ and Training and Education}

One area that is particularly important is the relationship of Cultural Intelligence is in working with virtual teams (Maznevski \& Chudoba, 2000). With the rapid increase in technology, many Multinational Corporations are doing global business virtually by employing individuals located in different countries who work as virtual teams. Particularly in the IT industry, we know from the outsourcing literature how frequently this is used. An increasing amount of international business is being conducted by individuals from different locations (Zhao, 2005). It is crucially important that each member of the team be culturally sensitive to every other member of the team. These individuals never see each other and are only connected by telephone, email, videoconferencing and other distance method technologies. Cultural intelligence is particularly relevant here as the importance of cultural sensitivity to each other in this team cannot be understated.

\subsection{CQ and the Role of Expectancy Disconfirmation}

One of the most significant and influential theories in the history of social psychology was the theory of cognitive dissonance developed by Leon Festinger (1957). Even today decades later after this theory was formulated by Leon Festinger, widespread applications have been found in many fields such as communication studies, marketing, and finance (e.g Littlejohn, 2010). According to this theory, disconfirmed expectancies create a state of psychological discomfort or dissonance because the outcome contradicts expectancies. Discrepancies between expectations and actual occurrences motivate discrepancy reduction efforts. Bhawuk (2009) states that in cross-cultural training, this expectancy disconfirmation plays an important role. For learning to occur, it is important that individuals experience disconfirmation of expectations, otherwise if expectations are met, they will respond automatically and habitually and practice behaviors that they already know, and true learning will not occur.

In a recent study, Rosenblatt, Worthley, and Macnab (2013) examined the role of experiential cultural intelligence education, and they found that expectancy disconfirmation was an important mediator in the learning process and the the development of CQ. They found that greater experience disconfirmation was associated with greater CQ development. We recommend that there should be more research in this area to understand how cultural intelligence can be developed, under conditions of expectancy disconfirmation, and how we can incorporate this into the training process.

To summarize future studies should examine the types of training needed and the effectiveness of these methods to enhance cross-cultural understanding that operate from Asia and the role of CQ in this process. Other important areas in Training could include mandatory expatriate training on CQ in these Asian countries. In addition one should also train the local population of the country that would receive the expatriates.

\subsection{CQ and Education}

Another area of research very relevant to CQ is Education. CQ can be learnt and taught and is a very important skill and competency to have in today's world as discussed earlier. CQ should be introduced as part of the curriculum and should be one skill and competency that the cross-cultural management competencies needed in today's workplace is also reflected in the accreditation process for the Association to Advance Collegiate Schools of Businesses (AACSB), where the AACSB stated "Complex demands on management and accounting education mirror the demands on organizations and managers" (AACSB, 2009, p. 4). Additionally, in the same document, the AASCB also stated that some of the challenges are:

"Differences in organizational and cultural values" and "cultural diversity among employees and customers"

Clearly, the accrediting bodies expect that universities and colleges offering graduate and undergraduate programs address these challenges.

However, in Asian there is very little research on the curriculum of courses offered for these programs in the light of these requirements. We suggest that in the future more research is needed to examine how students acquire these cultural competencies in Asia and what are the specific courses and types of education involved to 
address these requirements. Universities in Asian curriculum need to assess their programs as they have culture-specific needs in the curriculum and study the learning outcomes. More rigorous, systematic studies MacNab (2012) have to done to examine what are the learning outcomes in these courses and programs and how they are specifically related to the development of CQ. Longitudinal designs also need to be used as learning these skills and competencies may only be evident over time.

\section{Discussion}

In this paper, we discussed a promising area that has become popular in recent years. We proposed many areas of research and identified the need for research in specific areas specifically in the Asian context. The four important areas that need to be examined include how CQ can be measured in a culture-specific context, CQ and its relation to culture-specific variables, CQ and Emotional labor and CQ Education and Training in Asia. Although there are many other issues that could be addressed in the CQ area, the main limitation of this paper is that we focused only on four specific areas, we also limited our discussion to the Asian context. However, several propositions, hypotheses and research questions could be developed based on this paper to be tested by future researchers. This paper can significantly enhance the knowledge base for both CQ theory and CQ practice in Asia.

\section{References}

Allen, J. A., Diefendorff, J. M., \& Ma, Y. (2013). Differences in emotional labor across cultures: A comparison of Chinese and US service workers. Journal of Business and Psychology, 29(1), 21-35. http://dx.doi.org/10.1007/s10869-013-9288-7

Ang, S., Van Dyne, L., Koh, C., Ng, K. Y., Templer, K. J., Tay, C., \& Chandrasekar, N. A. (2007). Cultural intelligence: Its measurement and effects on cultural judgment and decision making, cultural adaptation and task performance. Management and Organization Review, 3(3), 335-37. http://dx.doi.org/10.1111/j.17408784.2007.00082.x

Bhawuk, D. P. S. (2009). Intercultural training for the global workplace: Review, synthesis, and theoretical explorations. Handbook of Culture, Organization, and Work, 462-488.

Bray, D. W., Campbell, R. J., \& Grant, D. L. (1974). Formative years in business: A long-term AT\&T study of managerial lives. New York: Wiley.

Briscoe, D. R. (1997). Assessment centers: Cross-cultural and cross-national issues. Journal of Social Behavior and Personality, 12, 261-270.

Brislin, R. W., \& Kim, E. S. (2003). Cultural diversity in people's understanding and uses of time. Applied Psychology, 52(3), 363-382. http://dx.doi.org/10.1111/1464-0597.00140

Brislin, R., Worthley, R., \& Macnab, B. (2006). Cultural intelligence understanding behaviors that serve people's goals. Group \& Organization Management, 31(1), 40-55. http://dx.doi.org/10.1177/1059601105275262

Crowne, D. P., \& Marlowe, D. (1960). A new scale of social desirability independent of psychopathology. Journal of Consulting Psychology, 24, 349-354.

Drucker, P. F. (2007). Management challenges for the 21st century. Routledge.

Earley, P. C., \& Ang, S. (2003). Cultural intelligence: Individual interactions across cultures. Stanford: Stanford University Press.

Earley, P. C., \& Mosakowski, E. (2004). Cultural intelligence. Harvard Business Review, 82(10), 139-146.

Elfenbein, H. A., \& Ambady, N. (2002). On the universality and cultural specificity of emotion recognition: A meta-analysis. Psychological Bulletin, 128(2), 203-235. http://dx.doi.org/10.1037/0033-2909.128.2.203

Farrell, D., \& Grant, A. J. (2005). China's looming talent shortage. The McKinsey Quarterly: The Online Journal of McKinsey \& Co., 5 .

Festinger, L. (1957). A Theory of Cognitive Dissonance. Palo Alto: Stanford Univ. Press, Stanford.

Flaherty, J. E. (2008). The effects of cultural intelligence on team member acceptance and integration in multinational teams. Handbook of cultural intelligence: Theory, measurement, and applications, 192-205.

Gudykunst, W. B., Ting-Toomey, S., \& Chua, E. (1988). Culture and interpersonal communication. Sage Publications, Inc.

Hochschild, A. R. (1979). Emotion work, feeling rules, and social structure. American Journal of Sociology, 85, 551-575. 
Hochschild, A. R. (1983). The managed heart: Commercialization of human feeling. Berkeley: University of California Press.

Hofstede, G. (1980). Culture's consequences: International differences in work-related values. Beverly Hills, CA.: Sage.

Hofstede, G. (2001). Culture's consequences: Comparing values, behaviors, institutions and organizations across nations. Beverly Hills, CA.: Sage.

Hofstede, G. (2003). Geert hofstede cultural dimensions. Retrieved January 25, 2015, from http://www.geert.hofstede.com

Hofstede, G., Hofstede, G. J., \& Minkov, M. (2010). Cultures and organizations; Software of the mind (3rd ed.). New York: McGraw Hill

Holtgraves, T. (1997). Styles of language use: Individual and cultural variability in conversational indirectness. Journal of Personality and Social Psychology, 73(3), 624-637.

Howard, A. (1997). A reassessment of assessment centers: Challenges for the 21st century. Journal of Social Behavior \& Personality, 12(5), 13-52.

Hülsheger, U. R., \& Schewe, A. F. (2011). On the costs and benefits of emotional labor: A meta-analysis of three decades of research. Journal of Occupational Health Psychology, 16(3), 361-389. http://dx.doi.org/10.1037/ a0022876

Kim, K., Kirkman, B. L., \& Chen, G. (2008). Cultural intelligence and international assignment effectiveness. Handbook of Cultural Intelligence. Theory, Measurement, and Applications, 71-90.

Kogut, B., \& Singh, H. (1988). The effect of national culture on the choice of entry mode. Journal of International Business Studies, 19(3), 411-432.

Lasserre, P., \& Schutte, H. (2006). Strategies for Asia Pacific: Meeting new challenges (3rd ed.). Basingstoke, Hampshire: Palgrave Macmillan.

Li, P. P. (2007). Toward an integrated theory of multinational evolution: The evidence of Chinese multinational enterprises as latecomers. Journal of International Management, 13(3), 296-318. http://dx.doi.org/10.1016/ j.intman.2007.05.004

Littlejohn, S. W., \& Foss, K. A. (2010). Theory of human communication. Waverly Press, Inc.

MacNab, B. R., \& Worthley, R. (2012). Individual characteristics as predictors of cultural intelligence development: The relevance of self-efficacy. International Journal of Intercultural Relations, 36(1), 62-71.

Matsumoto, D. (1990). Cultural similarities and differences in display rules. Motivation and Emotion, 14(3), 195-214.

Maznevski, M. L., \& Chudoba, K. M. (2000). Bridging space over time: Global virtual team dynamics and effectiveness. Organization Science, 11(5), 473-492

Menon, S., \& Narayanan, L. (2008). Cultural intelligence: strategic models for a Globalized economy. Journal of Global Management Research, 4(2), 27-32.

Menon, S., \& Narayanan, L. (2009). Cultural intelligence: an empirical examination of strategic models. Journal of Global Management Research, 5(3), 33-38.

Menon, S., \& Narayanan, L. (2011). A culture specific examination of expatriate leaders in two countries using a mixed method approach. Journal of Global Management Research, 7(3),44-47.

Menon, S., Narayanan, L., Plaisent, M., \& Bernard, P. (2011). Cultural Intelligence: A Culture-Specific Examination of Expatriate Leaders in Two Countries. Self, 8, 15.

Menon, S., Narayanan, L., \& Spector, P. E. (1996). Time Urgency and Its Relation to Occupational Stressors and Health Outcomes for Health Care Professionals. In C. D. Speilberger, \& I. Sarason (Eds.), Stress and Emotion. Washington DC : Taylor \& Francis

Mesquita, B., \& Delvaux, E. (2013). A cultural perspective on emotion labor. In A. A. Grandey, J. M. Diefendorff, $\&$ D. E. Rupp (Eds.), Emotional labor in the 21st century: Diverse perspectives on emotion regulation at work (pp. 251-272). New York, NY: Psychology Press/Routledge.

Narayanan, L., Menon, Menon, S., \& Spector, P. E. (1999) A cross-cultural cultural comparison of job stressors and reactions among employees holding comparable in two countries. International Journal of Stress 
Management, 6, 197-212.

Narayanan, L., Menon, S., \& Levine, E. L. (1995). Personality Structure : A Culture-Specific Examination of the Five-Factor Model. Journal of Personality Assessment, 64, 51-62.

Narayanan, L., Menon, S., \& Spector, P. E. (1999). Stress in the workplace: A comparison of gender and occupations. Journal of Organizational Behavior, 20, 63-73.

Nisbett, R. E. (2003). The geography of thought: How Asians and Westerners think differently - and why. London: Nicholas Brealey Publishing.

Pereira, A. A. (2004). State entrepreneurship and regional development: Singapore's industrial park inBatam and Suzhou. Entrepreneurship and Regional Development, 16(2), 129-144. http://dx.doi.org/10.1080/ 09585190601041067

Rosenblatt, V., Worthley, R., \& MacNab, B. (2013). From contact to development inexperiential cultural intelligence education: The mediating influence of expectancy disconfirmation. Academy of Management Learning \& Education, 12(3), 356-379. http://dx.doi.org /10.5465/amle.2012.0199

Shaffer, M., \& Miller, G. (2008). Cultural Intelligence. Handbook of cultural intelligence: Theory, measurement, and applications, 107.

Triandis, H. C. (2006). Cultural intelligence in organizations. Group \& Organization Management, 31(1), $20-26$. http://dx.doi.org/10.1177/1059601105275253

Triandis, H. C., Marin, G., Lisansky, J., \& Betancourt, H. (1984). Simpatía as a cultural script of Hispanics. Journal of Personality and Social Psychology, 47(6), 1363-1375.

Usunier, J. G. (1991). Business time perceptions and national cultures: A comparative survey. MIR: Management International Review, 31(3), 197-217

Van Dyne, L., Ang, S., \& Livermore, D. (2010). Cultural intelligence: A pathway for leading in a rapidly globalizing world. Leading Across Differences, 131-138.

Van Everdingen, Y. M., \& Waarts, E. (2003). The effect of national culture on the adoption of innovations. Marketing Letters, 14(3), 217-232. http://dx.doi.org/10.1023/A:1027452919403

Zhao, C. L. (2005). Management of corporate culture through local managers' training in foreign companies in China: A qualitative analysis. International Journal of Training and Development, 9(4), 232-255. http://dx.doi.org/10.1111/j.1468-2419.2005.00234.X

\section{Copyrights}

Copyright for this article is retained by the author(s), with first publication rights granted to the journal.

This is an open-access article distributed under the terms and conditions of the Creative Commons Attribution license (http://creativecommons.org/licenses/by/3.0/). 